\title{
The Effect of Foot Reflexology on Physiological Indicators and Mechanical Ventilation Weaning Time among Open-Heart Surgery Patients
}

\author{
Amira Elsayed Elsayed, Nahed Attia Kandeel', Wafaa Wahdan Abd El-Aziz \\ Critical Care and Emergency Nursing Department, Faculty of Nursing, Mansoura University, Egypt \\ *Corresponding author: Nahed_Kandeel2000@yahoo.com
}

Received February 14, 2019; Revised March 25, 2019; Accepted May 05, 2019

\begin{abstract}
Shortening the length of mechanical ventilation (MV) and lowering dose of sedatives among critically ill patients can decrease complications, intensive care length of stay and mortality rate. Therefore, introducing non-pharmacologic interventions such as reflexology became an issue of concern for critical care nurses. The purpose of this study was to investigate the effect of foot reflexology on physiological indicators and mechanical ventilation weaning time in open-heart surgery (OHS) patients. Methods: Quasi-experimental study with a convenience sampling technique was used to recruit 80 patients who underwent open heart operation and admitted to cardiothoracic intensive care unit (ICU) of Mansoura University Hospital. Random assignment was allocated to the intervention group (foot reflexology) and the control group (routine care). Data were collected using participants' physiological indicators and MV weaning time assessment tool. Results: There were statistical significant differences between the foot reflexology group and the control group concerning all physiological indicators $(p<0.05)$. Statistical significant differences were also noted on shortening the length of weaning time between both groups $(p<0.05)$. Conclusion: Foot reflexology is an effective method for stabilizing physiological indicators and decreasing ventilator dependence among patients undergoing OHS. Therefore, it can be introduced as an adjunct to daily care of OHS patients in ICU.
\end{abstract}

Keywords: foot reflexology, physiological indicators, mechanical ventilation weaning time, open heart surgery

Cite This Article: Amira Elsayed Elsayed, Nahed Attia Kandeel, and Wafaa Wahdan Abd El-Aziz, "The Effect of Foot Reflexology on Physiological Indicators and Mechanical Ventilation Weaning Time among Open-Heart Surgery Patients." American Journal of Nursing Research, vol. 7, no. 4 (2019): 412-419. doi: 10.12691/ajnr-7-4-2.

\section{Introduction}

Cardiovascular diseases (CVDs) are considered to be the first leading cause of death worldwide due to stroke and cardiac arrest. According to the World Health Organization, in 2016, 17.9 million people lost their lives due to CVDs representing 31\% of all global deaths [1].

This mortality rate is expected to increase in the following ten years [2]. Surgical interventions still play a critical role in prolonging life and improving patients who experience CVDs quality of life [3]. However, patients undergoing open heart operation may experience physical, psychological and cognitive problems [4].

After operation, OHS patients are transported directly to the cardiothoracic ICU to allow liberation from MV after stabilization of their cardiac and respiratory functions [5]. However, weaning from MV after cardiovascular surgery is still one of the most complex tasks. Moreover, the use of sedatives post cardiac surgery in ICU to improve MV tolerance and reduce metabolic demands during hemodynamic and respiratory instability is very common [6]. However, these agents have several negative consequences on patients' conditions, and may lead to prolongation of $\mathrm{MV}$, over-sedation, delirium, and hemodynamic instability [7].

Prolonged mechanical ventilation (PMV) is a serious complication following cardiovascular surgeries. Although it occurs with a low incidence (3-9.9\%), it is associated with increased morbidity, mortality and cost of health care services [8,9]. Furthermore, prolonged ICU length of stay after cardiac operation is associated with increasing cost and resources utilization [6,8]. Therefore, early extubation is considered to be an essential element of 'fast-track' management strategy after cardiac operation and is linked with shorter stay in ICU and lowered health care costs [10].

There are various pharmacological and non-pharmacological methods for reducing patients' stress, pain and anxiety [11]. However, there are several complications related to pharmacological management such as disturbed level of consciousness and increasing the risk of drug dependence [7]. Currently, Nonpharmacological interventions, such as distraction, relaxing music, relaxation techniques, massage therapy and biofeedback are used by nurses as measures for 
reducing patients' anxiety, and enhancing their healing and general health $[11,12]$.

Complementary therapies and non-pharmacological interventions are noninvasive, simple and less expensive, and have less or no adverse effects compared with pharmacological remedies [13]. Foot reflexology massage is one of the non-pharmacological techniques used in ICU. Reflexology is defines as a systematic practice that focuses upon stimulating feet's reflex points that correspond to a specific body part [14]. There are reflex points or zones in the feet correlated with all body parts. These zones form a chart of the body in the feet with the right foot corresponding to the right side of the body and the left foot corresponding to the left side of the body. In other words, the whole body represented in the feet. Hence, when a specific reflex area is excited, the cells of the body comply by creating a reflex effect on the corresponding organs, nerves, tissues, and muscles [15].

Some studies revealed that foot reflexology has immediate effects on reducing heart rate (HR), systolic and diastolic blood pressure (SBP \& DBP), and increasing arterial oxygen saturation $(\mathrm{SaO} 2)[16,17,18]$. These findings are worthy of getting the attention of critical care nurses as the improvement of vital signs without medications is a significant goal of care. Additionally, foot reflexology can be used to improve physiological indicators in unconscious patients in ICUs.

It had been proven that foot reflexology massage is an efficient technique in decreasing postoperative pain and the use of analgesics, as well as lowering anxiety levels [19]. Additionally, it has been reported that foot reflexology is a useful method for managing incision pain after coronary artery bypass graft surgery [20]. Reflexology is an effective method for improving muscle comfort by enhancing blood flow which stimulates the parasympathetic nervous system [21].

Reflexology was first discovered in Egypt as it was adopted by Egyptians in their daily lives including medical practices. The details of using this technique were detected in the finding of hieroglyphic mural in the pyramid of Saggara [22]. However, currently, the use of reflexology treatment in the Egyptian culture is very limited and unpopular in medical or nursing fields in spite of the proved benefits of this technique.

The effectiveness of foot reflexology on anxiety, pain, stress, fatigue, physiological indices, and sleep quality has been extensively investigated by previous studies in different countries [14,19,23,24,25]. However, research which investigated the effect of this intervention on shortening the length of $\mathrm{MV}$ weaning time in patients undergone OHS are scare. Therefore, this study was carried out to address this issue.

\subsection{Purpose}

The purpose of this study was to investigate the effect of foot reflexology on physiological indicators and the length of mechanical ventilation weaning time in patients undergone open-heart surgery.

\subsection{Research Hypotheses}

There were two research hypotheses for this study including:
1) Open-heart surgery patients who receive foot reflexology intervention will have better physiological indicators than those who do not receive this intervention.

2) Open-heart surgery patients who receive foot reflexology intervention will have shorter mechanical ventilation weaning time than those who do not receive this intervention.

\section{Method}

\subsection{Study Design and Setting}

This study has a quasi-experimental design. Participants' recruitment and data collection occurred at the cardio-thoracic ICU of Mansoura University Hospital, Egypt. This ICU includes 5 beds and it is well equipped with advanced technology and manpower needed for patient care. The nurse-patient ratio in this unit is nearly $1: 1$.

\subsection{Subjects}

The study involved a convenience sample of OHS patients who were admitted to the cardiothoracic surgery department and were subjected to OHS during the study period.

\subsubsection{Inclusion Criteria}

The inclusion criteria for eligible participants were patients in the age group ranged from 18 to 75 years old, HR of more than $60 \mathrm{~b} / \mathrm{m}$, a SBP of greater than $90 \mathrm{mmHg}$ and partial thromboplastin time of $>60$ seconds.

\subsubsection{Exclusion Criteria}

The exclusion criteria were patients who were subjected to emergency OHS, patients with foot related medical issue (like corn, callus, neuropathy, fungal skin infection or past scars) and those who received more than one inotropic drugs after operation. Patients who had pace-maker or intra-aortic balloon pump, patients who needed prolonged MV more than 24 hours, patients with disturbed conscious level and those who received sedatives before intervention were also excluded from the study.

\subsubsection{Sample Size}

Based on year 2016 census report of patients' admission to the cardio-thoracic surgery department (Mansoura University Hospital Census, 2017), the total number of subjects assigned to perform OHS was 400. Steve thompon equation was used to calculate the sample size, at $5 \% \infty$ error (95.0\% significance) and $20.0 \beta$ error $(80.0 \%$ power of the study) [26].

$$
n=\frac{N \times p(1-p)}{\left[\left[N-1 \times\left(d^{2} \div z^{2}\right)\right]+p(1-p)\right]}
$$

Where: $\mathrm{N}=$ Population size (400), $\mathrm{Z}=$ degree of standardization for $95.0 \%$ significance, it is equal to 1.96 , $\mathrm{d}=$ Error percentage $(0.05), \mathrm{P}=$ Percentage of occurrence of event or not, it is 0.5 . 
Accordingly, the sample size was determined to be 39.99. Totally, 80 patients were enrolled and randomly assigned to two groups (40 patients in each group):

- Reflexology group who received foot reflexology intervention 60 minutes after being admitted to the cardio-thoracic ICU.

- Control group who was given the ordinary care without foot massage.

\subsection{Data Collection Instruments}

Data were collected using participants' physiological indicators and $\mathrm{MV}$ weaning time assessment tool. It was developed by the primary investigator based upon relevant literature [16,24,27,28,29]. It consists of two parts:

Part I: Participants' Demographic and Health Profile data

This part collected participants' demographic data including age, sex, marital status, occupation and educational level. It also covered participants' health profile including admission date, medical diagnosis, surgery type, past medical and surgical history, smoking status, cardiac ejection fraction (EF) and pharmacological treatment.

Part II: Physiological Indicators and MV Weaning Time Observation Checklist

This part involved patients' physiological indicators including $\mathrm{HR}$, RR, SBP, DBP, MAP, and $\mathrm{SpO} 2$ which were monitored six times. The six measurement time-points included monitoring the physiological indicators immediately after admission to cardio-thoracic ICU, one hour after being admitted to the ICU, immediately after reflexology, 10 minutes after reflexology, immediately after extubation and 60 minutes after extubation by using an electronic monitor. The MV weaning time was defined as the duration between admission to the cardio-thoracic ICU and extubation. This time was calculated by minutes.

\subsection{Validity and Reliability of the Tool}

The content validity of the tool was assessed by seven experts from Critical Care and Emergency Nursing, and Medicine fields. Modifications were made accordingly. The reliability of the tool was tested using Cronbach's alpha test and found to be $91 \%$ which indicates high reliability tool.

\subsection{Pilot Study}

A pilot study was carried out to check the clarity, feasibility, and applicability of the data collection tool. It involved 8 patients (10\% of the total sample) who were not included in the study sample.

\subsection{Ethical Considerations}

An ethical approval was gained from the Ethics Committee of Faculty of Nursing (No. 108/2017). Informed consent was obtained from participants one day before the surgery after providing them with comprehensive information about the study including the aim, benefits, risks, procedure and duration. The voluntariness nature of participation was emphasized to all eligible patients. They were also informed that they had the right to discontinue at any stage without responsibility. Furthermore, confidentiality of participants' personal information was maintained.

\subsection{Data Collection}

\subsubsection{Preparation}

An official permission to conduct the study was obtained from the administrative authorities of Mansoura University Hospital. Before commencing the study, the primary investigator received practical training on how to apply foot reflexology by a reflexology specialist from 'The Egyptian Academy of Complementary Medicine in Cairo' in February 2018. The primary investigator interviewed patients who met the inclusion criteria one day before surgery to explain to them the nature of the research and to invite them to participate in the study. Patients who accepted to take part in this research were enrolled in the study. Patients' demographic data were obtained from their medical records. Allocation of participants was done the day before surgery by using lottery randomization technique through choosing one of two cards labeled group A (foot reflexology group) and group $B$ (control group).

\subsubsection{Selected Points}

Based on the claim of reflexologists, the points on the planter surface of the foot which may be responsible for stabilization of physiological indicators and reduction of ventilation dependence were chosen. These points included diaphragm, solar plexus, heart, and lung. Diaphragm reflex point runs along the horizontal crease just below the ball of the foot and involved in respiration. Solar plexus point (relaxation point) located at the midline below the ball of both feet. This point communicates with the whole nervous system and can trigger a major relaxing effect as well as diminish both of anxiety and stress. Heart reflex point is located on the bottom of the big toe of the planter aspect of both feet. This point regulates blood circulation and improves the function of the heart. Lung reflex point regulates breathing and oxygen level and keeps the chest and lungs open [16,30,31,32].

\subsubsection{Applying Foot Reflexology Technique}

The reflexology procedure was performed by the primary investigator. The steps of foot reflexology technique were adopted from Kunz and Kunz [31]. Reflexology group received foot reflexology intervention 60 minutes after being admitted to the cardio-thoracic ICU while the other group received the usual care of the unit without foot massage. In the reflexology group, the patient was assisted to lie down in supine position with raising the head of the bed to 30 degrees. First, the primary investigator removed any metal object (e.g. ring), washed and warmed her hands, and lubricated them with nontherapeutic baby oil to facilitate massaging. Then, she administered general foot massage and reflexology massage to the participant. The investigator put four fingers on the dorsal aspect of the patient's foot and utilized the thumb to make rotational pressure on lung and heart area of the sole. Reflexology massage for every foot lasted from 15 to 20 minutes. Thirty minutes session can 
provide therapeutic and relaxation benefits [18,33,34]. Data collection extended over a period of seven months between April and October 2018.

\subsection{Statistical Analysis}

Statistical Package for Social Sciences (SPSS) program version 22 and Medcalc statistical analysis software version 15.8 were used to analyze the collected data. Descriptive statistics were used to analyze the sample with 95\% confident interval. Qualitative data were expressed as frequency and percentage. Quantitative data were initially tested for normality using Kolmogorov-Smirnov and Shapiro-Wilk's test with data being normally distributed if $p>0.050$. Quantitative data (HR, RR, SBP, DBP, MAP, SPO2 \& MV weaning time) were expressed as mean \pm standard deviation (SD) if normally distributed or median and interquartile range (IQR) if not normally distributed. Chi-Square test or Fisher's exact test was used to assess the similarity between the two groups in terms of demographic characteristics. The non-parametric alternative Mann-Whitney $U$ test was used to compare MV weaning time between the groups. The repeated measures of analysis of variance (RM-ANOVA) test were also used to examine the differences between the two groups concerning variations of physiological parameters across the six measurement time points. The statistical significance level $P$ value was set at less than 0.05 .

\section{Results}

\subsection{Participants' Demographic Data and Baseline Characteristics}

Table 1 illustrated that $55 \%$ of the participants were males and $45 \%$ were females. The range of the patients' age was 18 to 75 years, with $36.3 \%$ were in age group of 51-60 years. Overall, the majority (81.25\%) were married, $43.7 \%$ had achieved a high school level of education, $36.2 \%$ were house wife and $36.2 \%$ were smokers. The majority of the participants (80 \%) had a good ejection fraction $\geq 50 \%$. The results show that $31.2 \%$ of the participants had diabetes mellitus and $42.5 \%$ had hypertension. There were no statistical significant differences between the reflexology and the control groups regarding demographic data $(p>0.05)$ which indicates similarity between the study groups before intervention.

Table 1. Participants' Demographic Data and Baseline Characteristics

\begin{tabular}{|c|c|c|c|c|c|c|}
\hline Variable & Category & 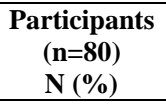 & $\begin{array}{c}\begin{array}{c}\text { Reflexology Group } \\
(\mathrm{n}=40) \\
\mathrm{N}(\%)\end{array} \\
\end{array}$ & $\begin{array}{c}\begin{array}{c}\text { Control Group } \\
(\mathrm{n}=40) \\
\mathrm{N}(\%)\end{array} \\
\end{array}$ & Significant test & $P$ value \\
\hline \multirow{2}{*}{ Gender } & Male & 44 (55\%) & 21 (52.5\%) & 23 (57.5\%) & \multirow{2}{*}{$\begin{array}{c}\text { Chi-Square Test } \chi^{2} \\
=0.202\end{array}$} & \multirow{2}{*}{0.822} \\
\hline & Female & $36(45 \%)$ & 19 (47.5\%) & 17 (42.5\%) & & \\
\hline \multirow{5}{*}{ Age (years) } & $18-30$ & 7 (8.8\%) & 5 (12.5\%) & $2(5 \%)$ & \multirow{5}{*}{$\begin{array}{c}\text { Chi-Square Test } \chi^{2} \\
=4.372\end{array}$} & \multirow{5}{*}{0.358} \\
\hline & $31-40$ & 17 (21.3\%) & 10 (25\%) & 7 (17.5\%) & & \\
\hline & $41-50$ & $16(20 \%)$ & 7 (17.5\%) & $9(22.5 \%)$ & & \\
\hline & $51-60$ & 29 (36.3\%) & 15 (37.5\%) & 14 (35\%) & & \\
\hline & $61-75$ & 11 (13.8\%) & $3(7.5 \%)$ & $8(20 \%)$ & & \\
\hline \multirow{3}{*}{ Marital status } & Single & 5 (6.25\%) & $2(5 \%)$ & 3 (7.5\%) & \multirow{3}{*}{$\begin{array}{l}\text { Fisher's exact test } \\
\qquad \chi^{2}=2.185\end{array}$} & \multirow{3}{*}{0.335} \\
\hline & Married & 65 (81.2\%) & 35 (87.5\%) & 30 (75\%) & & \\
\hline & Widow & 10 (12.5\%) & 3 (7.5\%) & 7 (17.5\%) & & \\
\hline \multirow{4}{*}{ Education } & Illiterate & $5(6.25 \%)$ & $2(5 \%)$ & $3(7.5 \%)$ & \multirow{4}{*}{$\begin{array}{l}\text { Fisher's exact test } \\
\qquad \chi^{2}=3.662\end{array}$} & \multirow{4}{*}{0.300} \\
\hline & Primary & $26(32.5 \%)$ & 17 (42.5\%) & 9 (22.5\%) & & \\
\hline & High-school & 35(43.7\%) & 15 (37.5\%) & $20(50 \%)$ & & \\
\hline & University & 14 (17.5\%) & $6(15 \%)$ & $8(20 \%)$ & & \\
\hline \multirow{5}{*}{ Occupation } & House wife & 29 (36.2\%) & 15 (37.5\%) & $14(35 \%)$ & \multirow{5}{*}{$\begin{array}{l}\text { Fisher's exact test } \\
\qquad \chi^{2}=1.198\end{array}$} & \multirow{5}{*}{0.878} \\
\hline & Employee & 19 (23.7\%) & 10 (25\%) & $9(22.5 \%)$ & & \\
\hline & Worker & $14(17.5 \%)$ & 7 (17.5\%) & 7 (17.5\%) & & \\
\hline & Unemployed & $9(11.25 \%)$ & 5 (12.5\%) & $4(10 \%)$ & & \\
\hline & Retired & 9 (11.25\%) & 3 (7.5\%) & $6(15 \%)$ & & \\
\hline \multirow{2}{*}{ Smoking } & yes & $29(36.2 \%)$ & $13(32.5)$ & $16(40 \%)$ & \multirow{2}{*}{$\begin{array}{c}\text { Chi-Square Test } \chi^{2} \\
=0.487\end{array}$} & \multirow{2}{*}{0.485} \\
\hline & No & 51(63.7\%) & 27 (67.5\%) & $24(60 \%)$ & & \\
\hline \multirow{2}{*}{$\begin{array}{l}\text { Ejection } \\
\text { Fraction }\end{array}$} & $(40-<50 \%)$ & $16(20 \%)$ & 9 (22.5\%) & 7 (17.5\%) & \multirow{2}{*}{$\begin{array}{c}\text { Chi-Square Test } \chi^{2} \\
=0.313\end{array}$} & \multirow{2}{*}{0.576} \\
\hline & $(\geq 50 \%)$ & $64(80 \%)$ & 31 (77.5\%) & 33 (82.5\%) & & \\
\hline \multirow{2}{*}{$\begin{array}{l}\text { Diabetes } \\
\text { mellitus }\end{array}$} & yes & $25(31.2 \%)$ & 12 (30\%) & 13 (32.5\%) & \multirow{2}{*}{$\begin{array}{c}\text { Chi-Square Test } \chi^{2} \\
=0.058\end{array}$} & \multirow{2}{*}{0.809} \\
\hline & No & $55(68.7 \%)$ & $28(70 \%)$ & $27(67.5 \%)$ & & \\
\hline \multirow{2}{*}{ Hypertension } & yes & 34 (42.5\%) & $18(45 \%)$ & $16(40 \%)$ & \multirow{2}{*}{$\begin{array}{c}\text { Chi-Square Test } \chi^{2} \\
=0.205\end{array}$} & \multirow{2}{*}{0.651} \\
\hline & No & 46 (57.5\%) & 22 (55\%) & 24 (60\%) & & \\
\hline
\end{tabular}

$\chi 2$ : Chi-square or Fisher's exact test, *Statistically significant $\mathrm{P} \leqslant 0.05$, N: Number of participants. 


\subsection{Physiological Indicators}

Table 2 compares between the physiological indicators of the study groups.

\subsubsection{HR}

A statistically significant decrease in the HR $(p<0.0005)$ was detected in foot reflexology group compared with the control group. Additionally, the mean HR was statistically significant between the two groups $(\mathrm{p}<0.0005)$.

\subsubsection{RR}

The participants in foot reflexology group showed significantly lower RR than participants in the control group $(\mathrm{p}<0.0005)$. Also, the mean $\mathrm{RR}$ was statistically significant between the two groups $(\mathrm{p}<0.0005)$.

\subsubsection{SBP}

A statistical significant reduction in the SBP was noted in foot reflexology group $(\mathrm{p}<0.0005)$. Moreover, the mean
SBP was statistically significant between the two groups $(\mathrm{p}<0.0005)$.

\subsubsection{DBP}

The DBP was statistically significant lower in foot reflexology group compared with the control group $(p<0.0005)$. As well, there was a statistically significant difference between the two groups regarding the mean DBP $(\mathrm{p}<0.0005)$.

\subsubsection{MAP}

There was a statistically significant drop in the MAP $(p<0.0005)$ in the reflexology group compared with the control group. Besides, the mean MAP was statistically significant between the two groups $(\mathrm{p}<0.0005)$.

\subsubsection{SPO2}

A statistical significant elevation in the SPO2 was found in the reflexology group compared with the control group $(\mathrm{p}<0.0005)$. The mean SPO2 was also statistically significant between the two groups $(\mathrm{p}<0.0005)$.

Table 2. Comparing Physiological Indicators between Foot Reflexology and Control Groups

\begin{tabular}{|c|c|c|c|c|c|c|c|c|}
\hline \multirow[t]{2}{*}{ Variable } & \multirow[t]{2}{*}{ Group } & On admission & $\begin{array}{l}\text { One hour after } \\
\text { admission }\end{array}$ & $\begin{array}{c}\text { Immediately } \\
\text { after reflexology }\end{array}$ & $\begin{array}{l}10 \text { minutes after } \\
\text { reflexology }\end{array}$ & After extubation & $\begin{array}{l}\text { One hour after } \\
\text { extubation }\end{array}$ & \multirow{2}{*}{$\begin{array}{l}\text { RM-ANOVA } \\
\text { Between Groups }\end{array}$} \\
\hline & & $\bar{x} \pm \mathrm{SD}$ & $\bar{x} \pm \mathrm{SD}$ & $\bar{x} \pm \mathrm{SD}$ & $\bar{x} \pm \mathrm{SD}$ & $\bar{x} \pm \mathrm{SD}$ & $\bar{x} \pm \mathrm{SD}$ & \\
\hline \multirow{2}{*}{ HR } & $\begin{array}{l}\text { Reflexology } \\
\text { Group }\end{array}$ & $99.75 \pm 18.938$ & $98.5 \pm 317.089$ & $92.75 \pm 14.588$ & $87.40 \pm 13.557$ & $85.40 \pm 11.084$ & $83.45 \pm 11.384$ & \multirow{2}{*}{$\begin{array}{c}\qquad \mathrm{F}=24.678 \\
\mathrm{P}<0.0005 \\
\text { Partial } \eta^{2}=0.240\end{array}$} \\
\hline & $\begin{array}{l}\text { Control } \\
\text { Group }\end{array}$ & $87.55 \pm 17.303$ & $90.50 \pm 16.928$ & $91.43 \pm 19.003$ & $90.58 \pm 17.840$ & $90.65 \pm 16.855$ & $89.93 \pm 16.505$ & \\
\hline \multirow{2}{*}{$\mathbf{R R}$} & $\begin{array}{l}\text { Reflexology } \\
\text { Group }\end{array}$ & $20.73 \pm 2.935$ & $20.80 \pm 3.575$ & $18.28 \pm 2.375$ & $17.35 \pm 1.272$ & $16.70 \pm 0.853$ & $16.85 \pm 0.864$ & \multirow{2}{*}{$\begin{array}{c}\mathrm{F}=24.534 \\
\mathrm{P}<0.0005 \\
\text { Partialn2 }=0.239\end{array}$} \\
\hline & $\begin{array}{c}\text { Control } \\
\text { Group }\end{array}$ & $18.13 \pm 2.919$ & $18.33 \pm 2.912$ & $18.08 \pm 2.141$ & $18.38 \pm 2.609$ & $18.35 \pm 2.348$ & $18.28 \pm 2.944$ & \\
\hline \multirow{2}{*}{ SBP } & $\begin{array}{l}\text { Reflexology } \\
\text { Group }\end{array}$ & $138.38 \pm 13.077$ & $143.33 \pm 13.379$ & $134.98 \pm 11.102$ & $129.20 \pm 9.227$ & $125.45 \pm 7.639$ & $121.40 \pm 7.588$ & \multirow{2}{*}{$\begin{array}{c}\mathrm{F}=18.701 \\
\mathrm{P}<0.0005 \\
\text { Partialn2 }=0.193\end{array}$} \\
\hline & $\begin{array}{l}\text { Control } \\
\text { Group }\end{array}$ & $136.60 \pm 15.357$ & $139.25 \pm 15.893$ & $134.20 \pm 15.756$ & $134.83 \pm 16.355$ & $138.38 \pm 15.585$ & $138.33 \pm 11.412$ & \\
\hline \multirow{2}{*}{ DBP } & $\begin{array}{l}\text { Reflexology } \\
\text { Group }\end{array}$ & $82.70 \pm 13.336$ & $85.85 \pm 13.609$ & $79.88 \pm 10.586$ & $77.08 \pm 10.450$ & $73.88 \pm 7.408$ & $70.63 \pm 6.205$ & \multirow{2}{*}{$\begin{array}{c}\mathrm{F}=12.629 \\
\mathrm{P}<0.0005 \\
\text { Partial } \eta^{2}=0.139\end{array}$} \\
\hline & $\begin{array}{c}\text { Control } \\
\text { group }\end{array}$ & $78.60 \pm 11.165$ & $79.33 \pm 10.269$ & $77.33 \pm 11.111$ & $76.93 \pm 10.719$ & $77.30 \pm 10.776$ & $80.60 \pm 9.08$ & \\
\hline \multirow{2}{*}{ MAP } & $\begin{array}{l}\text { Reflexology } \\
\text { Group }\end{array}$ & $97.50 \pm 14.157$ & $98.98 \pm 13.211$ & $93.23 \pm 13.712$ & $87.58 \pm 12.438$ & $83.83 \pm 12.900$ & $82.40 \pm 11.066$ & \multirow{2}{*}{$\begin{array}{c}\mathrm{F}=23.545 \\
\mathrm{P}<0.0005 \\
\text { Partial } \eta^{2}=0.232\end{array}$} \\
\hline & $\begin{array}{l}\text { Control } \\
\text { Group }\end{array}$ & $92.00 \pm 10.879$ & $93.48 \pm 13.091$ & $91.60 \pm 14.183$ & $90.73 \pm 12.884$ & $92.95 \pm 13.580$ & $92.65 \pm 15.610$ & \\
\hline \multirow{2}{*}{ SPO2 } & $\begin{array}{l}\text { Reflexology } \\
\text { Group }\end{array}$ & $97.80 \pm 2.452$ & $98.05 \pm \quad 3.080$ & $99.25 \pm 1.971$ & $99.90 \pm 0.632$ & $99.80 \pm 0.883$ & $99.93 \pm 0.474$ & \multirow{2}{*}{$\begin{array}{c}\mathrm{F}=39.601 \\
\mathrm{P}<0.0005 \\
\text { Partial } \eta^{2}=0.337\end{array}$} \\
\hline & $\begin{array}{l}\text { Control } \\
\text { Group }\end{array}$ & $98.95 \pm 2.099$ & $99.00 \pm 2.100$ & $98.73 \pm 2.331$ & $97.60 \pm 2.772$ & $96.23 \pm 3.134$ & $95.78 \pm 3.475$ & \\
\hline
\end{tabular}

$\bar{X}$ : Mean, SD: Standard Deviation, *Statistically significant $P \leq 0.05$.

Table 3. Comparing MV Weaning Time between Groups

\begin{tabular}{|c|c|c|c|c|}
\hline \multirow{2}{*}{ Statistic } & \multicolumn{2}{|c|}{ Group } & \multirow{2}{*}{ Significant test } & \multirow{2}{*}{$P$ value } \\
\cline { 2 - 3 } & Reflexology Group $(\mathrm{n}=40)$ & Control Group $(\mathrm{n}=40)$ & \\
& Median & 270 & 435 & Mann-Whitney U Test \\
value $=-7.230$ & Z & $<0.0005$ \\
\hline IQR & $195-300$ & $380-500$ & & \\
\hline Minimum & 120 & 300 & & \\
\hline Maximum & 420 & 800 & & \\
\hline
\end{tabular}

IQR: Inter-Quartile Range, Z value: Mann-Whitney U Test. 


\subsection{Weaning Time}

Table 3 showed that the median of MV weaning time in the reflexology group was 270 minutes while in the control group was 435 minutes. There was a statistically significant shorter weaning time in the reflexology group as compared to the control group ( $\mathrm{Z}$ value $=-7.230$, $\mathrm{p}<0.0005)$.

\section{Discussion}

\subsection{The Effect of Foot Reflexology on Physiological Indicators}

Our study focused on investigating the effect of foot reflexology on physiological indicators and the length of MV weaning time in patients undergone OHS. The findings of this study support the hypothesis that foot reflexology positively affects the stabilization of physiological indicators (HR, RR, SBP, DBP, MAP and SPO2) of critically ill patients and decreases ventilation dependence as compared with patients who did not receive foot massage. This improvement may be due to the presence of nearly 15000 nerves in the feet that enervate all body parts. Therefore, when applying reflexology technique it causes calmness for the nervous system [34]. Additionally, massaging reflexology areas of the lung on foot positively influences pulmonary function which in turn reduces ventilation dependence and facilitates liberation from MV. Moreover, massaging heart reflex point increases blood supply to the heart which enables the heart to pump the oxygen-rich blood around the body and improves oxygenation [31].

Our results are consistent with preceding studies which demonstrated the efficiency of foot reflexology technique in improving physiological indicators including $H R, R R$, SBP, DBP and SPO2 among various patient categories and in different settings $[17,18,24,32,35,36]$. Similarly, a study conducted by Khaledifar et al., [37] illustrated that there was a significant improvement in some of vital parameters including DBP, HR and RR in patients undergoing coronary angiography after reflexotherapy. However, they reported that the change in SBP was not significant. Also, Abbaszadeh et al., [16] reported that foot reflexology technique had a statistically significant influence on physiological parameters (SBP, DBP, MAP, RR and SPO2) except the HR. This could be because the investigators performed reflexology massage for heart reflex point only on the left foot. On the same line, our findings are consistent with other studies which obtained evidence that foot reflexology decreases SBP and DBP [30,38]. Additionally, Khalili et al., [39] revealed that foot reflexology has a positive effect on reducing SBP and DBP, but no significant effect was noted on HR or RR. Another study carried out by Azami et al., [40] found that foot reflexology reduces MAP among neurosurgical patients in ICUs. On the contrary, many research studies did not reveal the positive effect of foot reflexology on physiological parameters. This inconsistency could be due to many factors such as applying foot massage by two different individuals [28], recruiting small sample size
$[41,42]$ and variations in the number and duration of reflexology sessions [29].

Interestingly, one study investigated the cardiovascular effects of reflexology in healthy people illustrated that foot reflexology could increase BP and HR [43]. The investigators interpreted this finding as a positive outcome because reflexology co-activates two branches of autonomic nervous system which could be useful in enhancing hemostasis and healing process.

\subsection{The Effect of Foot Reflexology on MV Weaning Time}

The results of our study illustrated the effectiveness of reflexology treatment on shortening the length of MV weaning time. There is a paucity of studies which examined the effect of this intervention on the weaning time from MV. Ebadi et al., [28] investigated the effectiveness of reflexology on physiological parameters and MV weaning time in patients undergoing OHS in Iran. Similar to our results, they reported that the means of weaning time in the reflexology and the control groups were $283.43 \pm 96.26$ and $322.54 \pm 70.95$ minutes, respectively which indicates that the weaning time in the reflexology group was shorter than the control group. Similarly, our findings are supported by other previous studies which reported that reflexotherapy is an effective procedure in reducing the required level of sedation and analgesia for patients receiving MV $[27,35]$. This can lead to decrease the length of stay on $\mathrm{MV}$ and accelerate weaning process [44].

On the contrary, our study findings are contradicted with a previous study conducted by Ismail [45] who evaluated the effect of reflexology on physiological outcomes among mechanically ventilated patients in ICUs at Cairo University Hospitals. The investigator demonstrated that the mean duration of stay on MV in the reflexology group was $18.98 \pm 9.905$ while in the control group was $19.78 \pm 11.696$ with no significant differences detected between groups regarding stay on $\mathrm{MV}(\mathrm{t}=0.75$, $p=0.46)$. The researcher referred these findings to participants' medical diagnosis, chronic illness and co-morbidities

\section{Limitations}

There are two limitations for this study. First, the study was conducted in one cardiothoracic ICU in one teaching hospital. Second, the study involved a small sample size (80 patients). These two factors limit the generalizability of the research findings.

\section{Conclusion and Recommendations}

Based on the results of our study, we conclude that foot reflexology massage can significantly enhance the physiological indicators, and shorten MV weaning time in patients undergone OHS. Therefore, foot reflexology massage can be incorporated into daily patient care in cardiothoracic ICU. Training programs on applying foot 
reflexology for critical care nurses are needed. Future large scale studies on different patient population are also required in order to obtain a strong evidence to support this approach and enrich the body of knowledge in this area.

\section{Acknowledgements}

Our sincere appreciation is offered to all patients who agreed to participate in this study. We also acknowledge the assistance provided by the staff of the cardiothoracic ICU.

\section{Declaration of Conflicting Interests}

The authors declare no potential conflicts of interest with respect to the research or publication of the article.

\section{Funding}

The authors received no financial support for the research.

\section{References}

[1] World Health Organization. (2017). Cardiovascular diseases fact sheets. Available at

https://www.who.int/news-room/fact-sheets/detail/cardiovasculardiseases-(cvds). [Accessed May. 17, 2017].

[2] American Heart Association. (2015). Heart Disease and Stroke Statistics 2015: a report from American Heart Association. Available at http://circ.ahajournals.org.

[3] Urden, L., Stacy, K., \& Lough, M. Critical Care Nursing: Diagnosis and Management. St. Louis: Mosby. 2014.

[4] Shrestha, U., \& Adhikary, G. P. Problems faced by clients and factors affecting post-operative recovery after open-heart surgery in selected hospitals in Kathmandu, Journal of Institute of Medicine, 39(3). 73-77. 2019.

[5] French, J. Medical-surgical Nursing Made Incredibly Easy, Lippincott Williams \& Wilkins, Philadelphia, 2012.

[6] Liu, H., Ji, F., Peng, K., Applegate, R.L., \& Fleming, N. Sedation after cardiac surgery: Is one drug better than another? Anesthesia \& Analgesia, 124(4). 1061-1070. 2017.

[7] Vincent, J. L. Optimizing sedation in the ICU: the eCASH concept, Signa Vitae, 13(3), 10-13. 2017.

[8] Gumus, F., Polat, A., Yektas, A., Totoz, T., Bagci, M., Erentug, V., \& Alagol, A. Prolonged mechanical ventilation after CABG: risk factor analysis. Journal of Cardiothoracic and Vascular anesthesia, 29(1), 52-58. 2015.

[9] Trouillet, J. L., Combes, A., Vaissier, E., Luyt, C. E., Ouattara, A., Pavie, A., \& Chastre, J. Prolonged mechanical ventilation after cardiac surgery: outcome and predictors. The Journal of Thoracic and Cardiovascular Surgery, 138(4), 948-953. 2009.

[10] Wong, W. T., Lai, V. K., Chee, Y. E., \& Lee, A. Fast $\square$ track cardiac care for adult cardiac surgical patients. Cochrane Database of Systematic Reviews, (9), 2016.

[11] Gelinas, C., Arbour, C., Michaud, C., Robar, L., \& Côté, J. Patients and ICU nurses' perspectives of non $\square$ pharmacological interventions for pain management. Nursing in critical care, 18(6), 307-318. 2013

[12] Tracy, M. F., \& Chlan, L. Non-pharmacological interventions to manage common symptoms in patients receiving mechanical ventilation. Critical Care Nurse, 31(3), 19-28. 2011.

[13] Shahdadi, H., Mansouri, A., \& Bandani, E. The effect of foot reflexology massage on the anxiety of candidates for cataract surgery. Journal of Fundamental and Applied Sciences, 9(75), 1517-1525. 2017.

[14] Tarrasch, R., Carmel-Neiderman, N. N., Ben-Ami, S., Kaufman, B., Pfeffer, R., Ben-David, M., \&Gamus, D. The effect of reflexology on the pain-insomnia-fatigue disturbance cluster of breast cancer patients during adjuvant radiation therapy. The Journal of Alternative and Complementary Medicine, 1-7. 2017.

[15] The British Reflexology Association Ltd. (2013). About Reflexology. Available at: http://www.britreflex.co.uk/content/about-reflexology.

[16] Abbaszadeh, Y., Allahbakhshian, A., Seyyedrasooli, A., Sarbakhsh, P., Goljarian, S., \& Safaei, N. Effects of foot reflexology on anxiety and physiological parameters in patients undergoing coronary artery bypass graft surgery: A clinical trial. Complementary Therapies in Clinical Practice, 31(2018), 220-228. 2018.

[17] Shahsavari, H., Abad, M. E. E., \&Yekaninejad, M. S. The effects of foot reflexology on anxiety and physiological parameters among candidates for bronchoscopy: A randomized controlled trial. European Journal of Integrative Medicine, 12(2017), 177-181. 2017.

[18] Sheikh, S., Yaghoubinia, F., \&Navidian, A. Impact of Foot Reflexology Massage on the Patients' Physiological Indicators without Trauma with Loss of Consciousness in the Intensive Care Unit. Indian Journal of Public Health Research \& Development, 8(2), 201-206. 2017.

[19] Koraş, K., \&Karabulut, N. The Effect of Foot Massage on Postoperative Pain and Anxiety Levels in Laparoscopic Cholecystectomy Surgery: A Randomized Controlled Experimental Study. Journal of PeriAnesthesia Nursing, 1-8. 2018.

[20] Sadeghi Shermeh, M., Bozorgzad, P., Ghafourian, A., Ebadi, A., Razmjoei, N., Afzali, M., \& Azizi, A. Effect of foot reflexology on sternotomy pain after coronary artery bypass graft surgery. Iranian Journal of Critical Care Nursing Summer, 2, 51-4. 2009.

[21] Ray, B. S., Natha, H., \& Nageshwar, V. Foot reflexology: effect on pain and anxiety in post-operative patient. International Education and Research Journal, 3(5), 49-51. 2017.

[22] Embong, N. H., Soh, Y. C., Ming, L. C., \& Wong, T. W. Revisiting reflexology: Concept, evidence, current practice, and practitioner training. Journal of Traditional and Complementary Medicine, 5(4), 197-206. 2015.

[23] Chandrababu, R., Rathinasamy, E. L., Suresh, C., \& Ramesh, J. Effectiveness of reflexology on anxiety of patients undergoing cardiovascular interventional procedures: A systematic review and metaanalysis of randomized controlled trials. Journal of Advanced Nursing, 75(1), 43-53. 2019.

[24] Kaur, J., Kaur, S., \& Bhardwaj, N. Effect of foot massage and reflexology on physiological parameters of critically ill patients. Nursing and Midwifery Research, 8(3), 223-33. 2012.

[25] Mahmoudirad, G., GhaediMosolo, M., \&Bahrami, H. Effect of foot reflexology on anxiety of patients undergoing coronary angiography. Iran J Crit Care Nurs, 6(4), 235-242. 2014.

[26] Peacock, J. \& Peacock, P. Oxford handbook of medical statistics, Oxford University Press Inc, New York, 2011.

[27] Asadizaker, M., Fathizadeh, A., Haidari, A., Goharpai, S., \&Fayzi, $\mathrm{S}$. The effect of foot and hand massage on postoperative cardiac surgery pain. International Journal of Nursing and Midwifery, 3(10), 165-169. 2011.

[28] Ebadi, A., Kavei, P., Moradian, S. T., \& Saeid, Y. The effect of foot reflexology on physiologic parameters and mechanical ventilation weaning time in patients undergoing open-heart surgery: A clinical trial study. Complementary Therapies in Clinical Practice, 21(3), 188-192. 2015.

[29] Rahmani, Z., Rejeh, N., Heravi-Karimooi, M., Tadrisi, S. D., \& Vaismoradi, M. Effect of hand reflexology on anxiety and physiological variables among patients hospitalized in the cardiac care unit: A randomized placebo controlled clinical trial. Journal of Nursing Education and Practice, 8(4), 35-42. 2017.

[30] El-Refaye, G. E., \& Elsisi, H. F. E. M. The blood pressure response to foot reflexology adjunct to transcendental meditation training on postmenopausal hypertension. Physical Therapy and Rehabilitation, 4(4), 1-8. 2017.

[31] Kunz, B., \& Kunz, K. Complete reflexology for life, Dorling Kindersley Limited publishing, United States, 2007.

[32] Mansouri, A., Shadadi, H., Poudineh-Moghadam, M., Vahed, A. S., \&Dehghanmehr, S. Evaluation of the effect of foot reflexology massage on vital signs and anxiety after blood transfusions in 
children with thalassemia. Bali Medical Journal, 6(3), 623-629. 2017.

[33] Dalal, K., Maran, V. B., Pandey, R. M., \& Tripathi, M. Determination of efficacy of reflexology in managing patients with diabetic neuropathy: A randomized controlled clinical trial. Evidence-Based Complementary and Alternative Medicine, 2014, 1-11. 2014.

[34] Stillerman, E. Modalities for Massage and Bodywork, Elsevier Health Sciences, St. Louis, Missouri, 2016.

[35] Korhan, E. A., Khorshid, L., \&Uyar, M. Reflexology: its effects on physiological anxiety signs and sedation needs. Holistic nursing practice, 28(1), 6-23. 2014.

[36] Ghazavi, A., Pouraboli, B., Sabzevari, S., \&Mirzaei, M. Evaluation of the effects of foot reflexology massage on vital signs and chemotherapy-induced anxiety in children with leukemia. Medical-Surgical Nursing Journal, 4(4), 41-48. 2016.

[37] Khaledifar, A., Nasiri, M., Khaledifar, B., Khaledifar, A., \&Mokhtari, A. The effect of reflexotherapy and massage therapy on vital signs and stress before coronary angiography: An open-label clinical trial. ARYA Atherosclerosis, 13(2), 50-55. 2017.

[38] Elshamy, K., \& Elsafety, E. Effect of nursing interventions using foot reflexology on blood pressure and quality of life of hypertensive patients at mansoura university hospitals: preliminary results. The Medical Journal of Cairo University, 79(2), 193-202. 2011.

[39] Khalili, A., MasoudiAlavi, N., Mardani, D., Pour, N. B., Paymard, A., Daraei, M.,... \& Vardanjani, M. M. The effect of foot reflexology on physiological parameters. International Journal of Medical Research \& Health Sciences, 5 (9), 50-54. 2016.

[40] Azami, H., Paveh, B. K., Rezaei, M., \& Samadzadeh, S. The impacts of short-term foot massage on mean arterial pressure of neurosurgical patients hospitalized in intensive care units. Iranian Journal of Critical Care Nursing, 8(3), 133-142. 2015.

[41] Rollinson, K., Jones, J., Scott, N., Megson, I. L., \& Leslie, S. J. The acute (immediate) effects of reflexology on arterial compliance in healthy volunteers: A randomised study. Complementary Therapies in Clinical Practice, 22(2016), 16-20. 2016.

[42] Jones, J., Thomson, P., Lauder, W., Howie, K., \& Leslie, S. J. Reflexology has no immediate haemodynamic effect in patients with chronic heart failure: a double blind randomised controlled trial. Complementary Therapies in Clinical Practice, 19(3), 133-138. 2013.

[43] Ruiz-Padial, E, López, N. T., Bujaldón, J. L., Villanueva, I. E., \& del Paso, G. R. Cardiovascular effects of reflexology in healthy individuals: evidence for a specific increase in blood pressure. Alternative Medicine Studies, 2(4), 10-17. 2012.

[44] Chen, H. B., Liu, J., Chen, L. Q., \& Wang, G. C. Effectiveness of daily interruption of sedation in sedated patients with mechanical ventilation in ICU: A systematic review. International Journal of Nursing Sciences, 1(4), 346-351. 2014.

[45] Ismail, M. (2017). Effect of reflexology treatment on physiological outcomes among mechanically ventilated patients. (Master Dissertation, Cairo University).

(C) The Author(s) 2019. This article is an open access article distributed under the terms and conditions of the Creative Commons Attribution (CC BY) license (http://creativecommons.org/licenses/by/4.0/). 